\title{
TRIBOLOGICAL COMPENSATION FOR REDUCED PROPERTIES OF PARTS DURING OPERATION
}

\author{
Sergey Strebkov, Andrey Bondarev, Alexey Slobodyuk, Elena Vasilenko \\ Belgorod State Agricultural University named after V. Gorin, Russia \\ serwastr@gmail.com, av.bondarev@gmail.com,asp122@yandex.ru, elena.vasilenko2602@mail.ru
}

\begin{abstract}
To obtain maximum profit in the production of agricultural products, it is necessary to reduce the operating costs of machine and tractor units and agricultural machinery. They depend on such properties of the reliability of machines as reliability, durability and maintainability. These properties are formed during the design, production and operation of units and assemblies. The most expensive structural and assembly unit of a machine is the internal combustion engine, the cost of which can be $35 . . .40 \%$ of its total cost. As a rule, the residual life of engine parts before repair is $85 . .100 \%$. An important task of the service department is to carry out repairs - a set of organizational and technological measures to restore the serviceable (efficient) state, as well as renew the resource. There is a need to increase the engine life after repair. One of the rational ways to solve this problem is tribological compensation for the loss of the imparted properties of parts during the operation of machines, the use of additional antiwear additives to engine oils. To ensure the durability of the D-240 engine after major overhauls to the new level, it is recommended to use the AMOIL additive to the M-10G2 (SAE 30API CC) engine oil. The increase in wear of steel 45 caused by a decrease in hardness from 55 to $35 \mathrm{HRC}$, in the load range corresponding to the operating mode of the crankshaft, is tribologically compensated by the introduction of the AMOIL antiwear additive into the engine oil in an amount not exceeding $1 \%$ by weight. Operational tests have established that the AMOIL additive added to engine oil in a concentration of $0.22 \ldots 0.52 \%$ recommended for crankshaft hardness $51 \ldots 43 \mathrm{HRC}$ after repair reduces the wear rate of friction surfaces and thus increases the engine resource by $18.6 \%$ at the theoretically set $20 \%$.
\end{abstract}

Keywords: reliability, durability, additive, wear, engine.

\section{Introduction}

To obtain the maximum profit in the production of agricultural products, it is necessary to reduce the operating costs of machine-tractor units and agricultural machines. They depend on such properties of machine reliability as dependability, durability and maintainability [1]. These properties are formed during the design, production and operation of components and aggregates. The most expensive structural and assembly unit of the machine is the internal combustion engine, the cost of which can be $35 . . .40 \%$ of its total cost. As a rule, the residual life of engine parts before repair is $85 \ldots 100 \%$. An important task of the service department is to perform repairs - a set of organizational and technological measures to restore a serviceable (working) state and renew the resource. At the same time, expenditure of monetary funds is reduced by reducing the consumption of spare parts.

The service life of the engine before reaching the limit state consists of the pre-repair and the amount of inter-repair resources. The standards established that the resource of overhauled engines of automotive and tractor equipment should be at least $80 \%$ of the resource of new ones. However, practice shows that the resource of the repaired equipment has a lower level and is, according to various estimates, 30-60\% of the resource of the new one [2]. Failures that lead to malfunction of the engines can occur due to fatigue of materials, aging, residual deformations, corrosion and wear of the friction surfaces, as well as the loss of the attached properties. The greatest number of failures (50-75\%) occurs due to wear and tear [3;4]. The wear rate of working surfaces may increase after repair due to a decrease in the physical and mechanical properties of the material of the parts during operation or after technological operations that are necessary for repair. The task of the engineering and technical service is to increase the service life (resource) of machine components and assemblies during operation, which will lead to an increase in the depreciation period before the onset of the limit state.

The fundamental prerequisites for solving the problem of improving the reliability of machines by tribological methods were determined by Bowden F. P., Tabor D. [5] This scientific approach found its further development in the elaboration of surface-active antifriction additives with anti-wear action for internal combustion engines [6,7], in studying the tribochemical and tribophysical mechanisms of their action [8], and in the determination of the features of their application [9].

The number of engine overhauls during the service life can be determined by the formula:

$$
n_{k p}=k_{k p} \cdot k_{n} \cdot T_{m p},
$$


where $k_{k p}$ - annual coverage coefficient of engine overhaul;

$k_{n}$ - correction coefficient for the annual coverage coefficient $\mathrm{r}$ for major repairs of the engine, taking into account the place of operation of the tractor;

$T_{m p}$ - duration of engine operation before decommissioning (in years).

In connection with the above, there is a need to increase the engine resource after repair, as a result of which the engine operation time will increase before decommissioning (resource).

The engine resource is limited by the parts of the cylinder-piston group and the crank mechanism. According to literary sources, the greatest decrease in wear resistance after repair occurs in the surface matching "crankpin - bearing insert" [10]. Thus, this friction unit is the weakest link that limits the life of the engine, and, therefore, the coefficient of durability of the crankshaft can be equated with the coefficient of change in the pre-repair life of the engine after major repairs.

The main defect of parts that limit the life of the engine is the wear of their friction surfaces. Wear of working surfaces during repair is eliminated mainly by processing for the repair size. When restoring the crankpins by regrinding to the repair size, it is almost impossible to ensure their $100 \%$ resource. This is due to the fact that the hardness of the crankpins hardened by high-frequency currents decreases from the surface to the center of the shaft and the hardest wear-resistant layer is removed during grinding. The properties imparted to the crankpin change and the post-repair resource decreases.

After reaching the size limit, the crankshaft journals can be repaired by coating. However, wearresistant coatings, due to their hardness and brittleness, lead to a decrease in the fatigue resistance of the restored crankshafts. When solving this problem, it is advisable to use a coating with a lower tensile strength, less wear-resistant, but more plastic [11]. In this case, fatigue resistance determines the quality of restoration of worn crankpins.

The durability of the crankshafts, determined by the fatigue resistance and wear resistance, can be represented as:

$$
K_{D}=K_{W} \times K_{E},
$$

where $K_{D}$ - crankshaft durability coefficient;

$K_{W}$ - coefficient of wear resistance of the crankshaft friction surfaces;

$K_{E}-$ coefficient of endurance of the crankshaft.

It is possible to increase the coefficient of crankshaft life by increasing the coefficient of wear resistance by reducing the rate of wear of the friction surfaces. The crankshaft endurance coefficient after grinding decreases to 0.9 [12], and during coating, as a rule, it remains at the level of the extremely worn part, and therefore it is practically impossible to increase the durability coefficient to unity.

Reducing the wear rate is proposed by tribological compensation for the loss of the imparted properties of parts during operation in conjunction. This is possible by additional dosed introduction of anti-wear additives into lubricants during operation. The use of an anti-wear additive is more preferable than strengthening the friction surface of the crankshaft, since it does not require special repair equipment. In addition, the additive acts in a complex way, increasing the wear resistance of all parts lubricated with engine oil, and not just the crankshaft. The necessary concentration of the additive in the engine oil, which provides a coefficient of wear resistance equal to one, can be determined by the method described in $[13 ; 14]$.

In the case of boundary friction, when the main wear of the surfaces of the friction units occurs, moderate adhesive and corrosion-mechanical wear are the leading ones. Anti-wear additives, interacting with the friction surfaces, create strong protective layers on them, which protect the base metal from direct contact. These films can be formed as a result of physical adsorption, chemisorption, chemical reaction of additives with the surface metal, selective transfer, and tribopolymerization. Under normal friction, a dynamic balance is established between the destruction and the renewal of the protective surface layers. The decrease in the wear rate occurs due to the fact that wear protective films consist mainly of anti-wear additive materials and slightly of the metal of the friction surface.

The scheme illustrating the increase in the service life of the crankpins after repair as a result of the action of the anti-wear additive is shown in Fig. 1. 


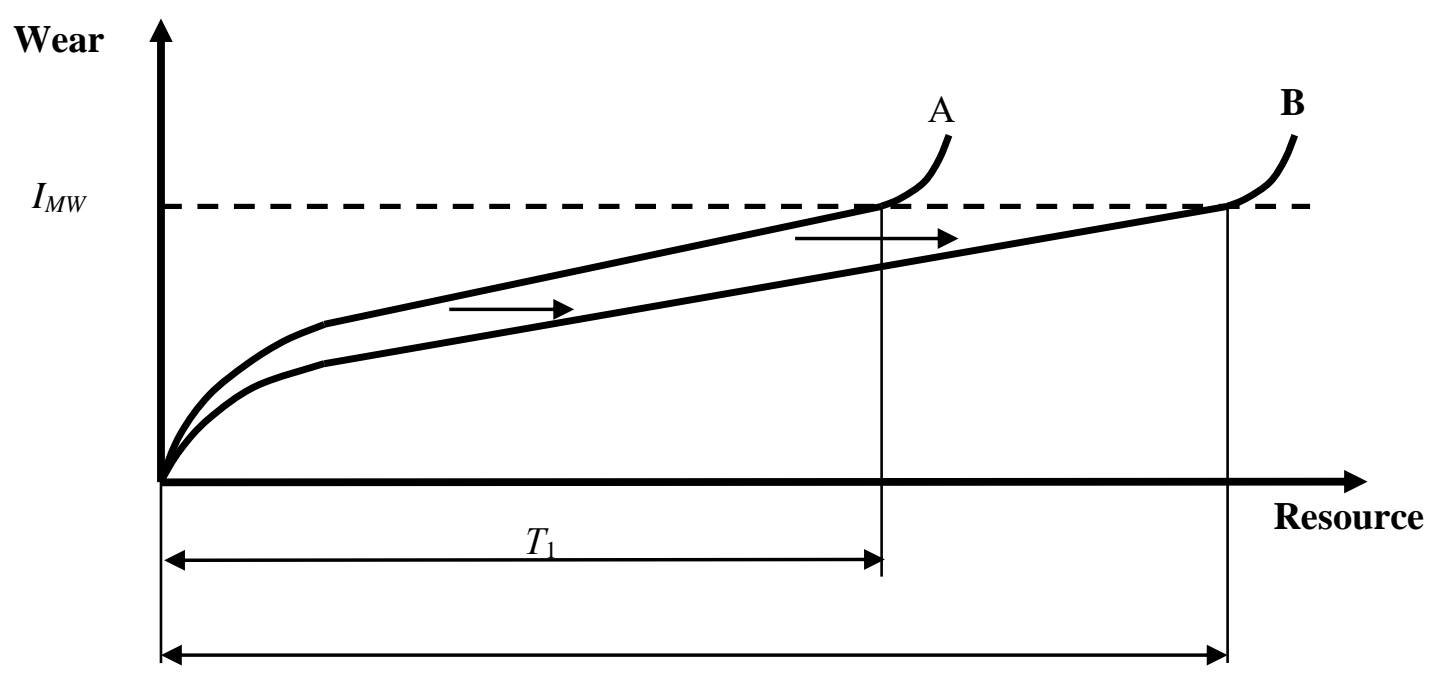

Fig. 1. Scheme of changing the resource of the part: $I_{M W}-$ maximum wear of the part; A - wear curve of the shaft after grinding to the repair size, without the use of an additive; B - wear curve of a new shaft without an additive, or a shaft after grinding to an oversize with an additive;

$T_{1}$ - shaft resource after grinding to the repair size when working without the use of an additive; $T$ - resource of a new crankshaft; $T_{2}$ - resource of the crankshaft after grinding to oversize when working with an additive

The use of an anti-wear additive is more preferable than strengthening the friction surface of the crankshaft, since it does not require special repair equipment. In addition, the additive acts in a complex way, increasing the wear resistance of all parts lubricated with engine oil, and not just the crankshaft. The necessary concentration of the additive in the engine oil, which provides a coefficient of wear resistance equal to one, can be determined by the method described in [15].

The increase in the service life and service cycles of the engine over its life cycle with the introduction of an anti-wear additive into the engine oil is illustrated in Fig. 2.

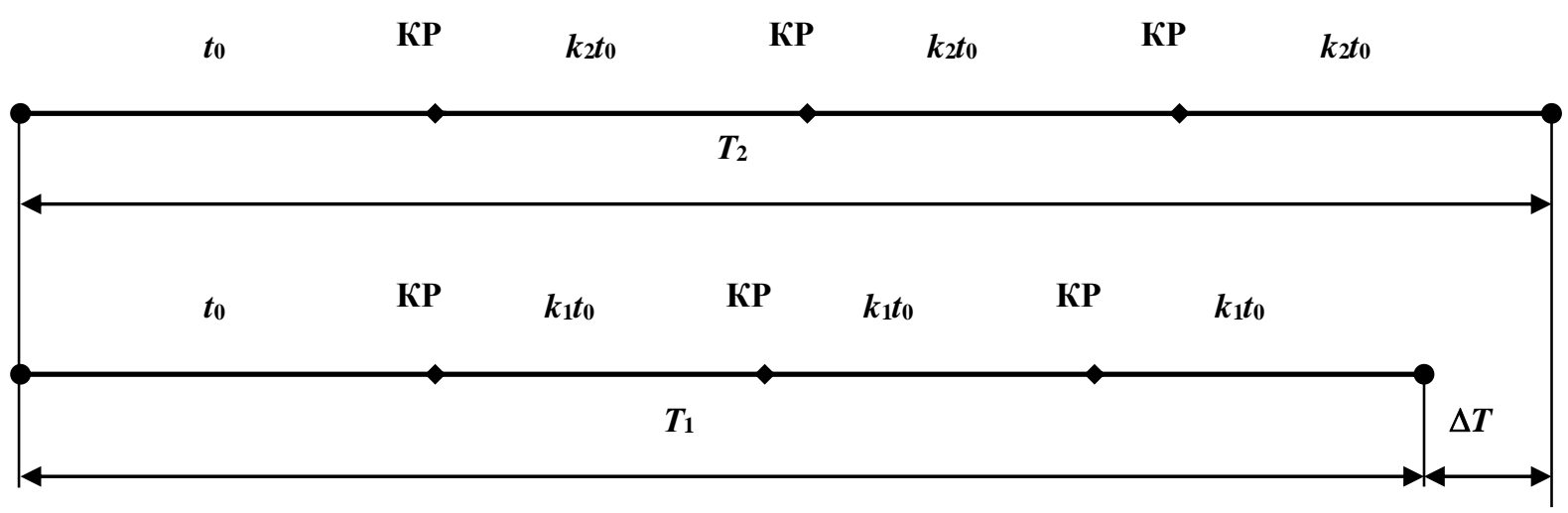

Fig. 2. Overhaul scheme: $T_{1}, T_{2}$ - engine life during operation, respectively, without the introduction and with the introduction of an additive; $\Delta T$ - increase in the engine life, moto-hour.; to - pre-repair service life of the engine; $k_{1}, k_{2}$-coefficient of change in the pre-repair service life of the engine after major repairs, respectively, without the introduction and with the introduction of an additive $\left(k_{1}=0.8, k_{2}=0.9\right)$

The increase in the engine life can be determined by the formula:

$$
\Delta T=T_{2}-T_{1}=t_{0} k_{\kappa p}\left(k_{2}-k_{1}\right),
$$

The coefficient of increasing the engine life can be determined by the formula:

$$
\varepsilon=\frac{T_{2}}{T_{1}}=\frac{1+n_{\kappa p} k_{2}}{1+n_{\kappa p} k_{1}},
$$

In our case, when determining wear, the response function has the form: 


$$
I=f(H R C, N, C),
$$

where $I-$ wear of the friction surface, $\mathrm{mg}$;

$H R C$ - friction surface hardness, HRC;

$N$ - amount of load on the samples during the test;

$C$ - concentration of the anti-wear additive in the lubricant, in $\%$ by weight.

The dependence of wear on various factors, as a rule, is non-linear. Therefore, the response function (5) is approximated by a second-order polynomial, which in our particular case takes the form:

$$
\begin{aligned}
& I=a_{0}+a_{1} H R C+a_{2} N+a_{3} C+a_{12} H R C \cdot N+ \\
& +a_{13} H R C \cdot C+a_{23} N \cdot C+a_{11} H R C^{2}+a_{22} N^{2}+a_{33} C^{2},
\end{aligned}
$$

where $a_{0}, a_{1}, a_{2}, a_{3}, a_{12}, a_{13}, a_{23}, a_{11}, a_{22}, a_{33}$ - coefficients that characterize the free term of the equation, linear and quadratic effects of the interaction of the corresponding factors.

\section{Materials and methods}

To determine the coefficients of the regression equation (6), an active laboratory experiment is performed. The tests are carried out on a roller friction machine of the SMT 2070 type according to the "pad-roller" scheme in the sliding friction mode.

The lubricating medium, which was subjected to tribological correction, is M-10G2 base engine oil. The anti-wear and anti-friction additive AMOIL was used as a corrector. It is the product of the interaction of oleic acid and ammonia in the presence of an alcoholic solution of iodine. It is a complex of neutralized oleic acid, oleic acid amide with the general formula $\mathrm{R}-\mathrm{CONH}_{2}$, and oleic acid ethyl ether with the general formula R-COO- $\mathrm{C}_{2} \mathrm{H}_{5}$, in which iodine exists as an iodide ion and an oleic acid salt complex representing iodine oleate $[16 ; 17]$.

During the experiment, the range of changes in the hardness of the tested friction surface should include the hardness of the new part and the surface hardness of this part obtained during regrinding, as well as the hardness for various types of surface restoration. To reduce the time spent on laboratory tests, wear is accelerated by any of the input factors. In our case, it is advisable to force the wear on load. The test load is varied to cover the widest range of friction and wear conditions. It should be borne in mind that the friction regime during testing should not qualitatively differ from the friction regimes corresponding to the operating conditions, so that the physical picture of the real wear process does not distort. The concentration of the additive should vary from 0 to values that are limited by the chemical properties of the lubricant used for the friction unit, the economic feasibility, or the concentration at which the anti-wear properties do not improve.

For an experiment in which three factors change at three levels, the most acceptable in our conditions is a three-level Box-Behnken second-order design. It includes 15 experiments, instead of 27 at a full factorial experiment. Although the plan we have chosen is not orthogonal, it is preferable to central compositional plans of the second order. It does not require the setting of factors on the axial distances beyond the originally chosen range. When setting up this kind of experiment, this presents significant difficulties. The three-level Box-Benkin plan for three factors is almost rotatable and has high efficiency according to all criteria of optimality $\left(e^{D}=0.879 ; e^{A}=0.935 ; e^{Q}=0.957 ; e^{E}=0.739\right)$.

The area of variation of the hardness of the working surface of the roller was chosen in the range $35 . . .55 \mathrm{HRC}$ with a step of 10 units. The upper hardness value of the working surface corresponds to the nominal hardness of the crankpins. The lower hardness value corresponds to the hardness obtained after reconditioning by surfacing.

The load was changed in the range of $700 \ldots 1000 \mathrm{~N}$ with a step of $150 \mathrm{~N}$. As the upper limit of loading, the highest value of the load was taken, at which the test was carried out without setting and scuffing. As the lower load limit, the value of the load at which wear was observed during the test, fixed by the selected method, is set. The load value of $1000 \mathrm{~N}$ corresponds to the operation of the part in very severe conditions, close to emergency. This correspondence is due to the fact that with a further slight increase in the load when using M-10 G2 oil, the oil film is destroyed, and catastrophic wear occurs. A load value of $700 \mathrm{NH}$ corresponds to light working conditions. This is due to the fact that at this load the wear is insignificant and with its further decrease, the wear becomes so small that it cannot be fixed. 
In our opinion, the actual operating conditions correspond to the range from 800 to $900 \mathrm{~N}$, which corresponds to the loads that occur in the surface matching "crankpin - bearing insert".

The concentration of the anti-wear additive in the engine oil varied in the range from 0 to $1 \%$ by weight in increments of $0.5 \%$. The lower value of the range corresponds to the test on pure commercial oil. The upper value corresponds to the concentration of the additive (according to the results of previous experiments), at which there is no further significant reduction in wear when it increases (Table 1).

Table 1

Factor levels and variation intervals

\begin{tabular}{|c|c|c|c|c|c|c|}
\hline \multirow{3}{*}{ Factor levels } & \multicolumn{3}{|c|}{ Natural values } & \multicolumn{3}{c|}{ Code values } \\
\cline { 2 - 7 } & $\begin{array}{c}\text { Additive } \\
\text { concentration C, \% }\end{array}$ & $\begin{array}{c}\text { Hardness, } \\
\text { HRC }\end{array}$ & Load, N & \multirow{2}{*}{ X1 } & \multirow{2}{*}{ X2 } & \multirow{2}{*}{ X3 } \\
\cline { 2 - 7 } & $\mathbf{X 1}$ & $\mathbf{X 2}$ & $\mathbf{X 3}$ & & & - \\
\hline Variation intervals & $0 \ldots$ & $35 \ldots 55$ & $700 \ldots 1000$ & - & - & - \\
\hline Basic level & 0.5 & 45 & 850 & 0 & 0 & 0 \\
\hline Upper level & 1.0 & 55 & 1000 & +1 & +1 & +1 \\
\hline Lower level & 0.0 & 35 & 700 & -1 & -1 & -1 \\
\hline
\end{tabular}

\section{Results and discussion}

When studying a lubricating composition based on M-10G2 engine oil and AMOIL additive, changes in the chemical characteristics of the oil were within acceptable values. According to the results of tribological studies, the mathematical model of compensation for the loss of operational properties wear resistance- (for steel 45 in the D-240 engine), depending on the surface hardness, the load value and the concentration of the anti-wear additive in the lubricating oil (6), took the following form:

$$
\begin{aligned}
& I=8.874-0.2903 \cdot H R C+0.002611 \cdot N-4.625 \cdot C+0.808 \cdot H R C \cdot C- \\
& -0.002055 \cdot N \cdot C+0.001962 \cdot H R C^{2}+0.985 \cdot C^{2}
\end{aligned}
$$

To determine the required minimum concentration of the AMOIL anti-wear additive, graphs of the concentration dependence on the surface hardness of the part after repair at various load values are presented (Fig. 3). To provide compensation for the wear resistance of the surface matching "crankpin - bearing insert" after engine overhaul to the level of a new surface matching, provided that repairs are carried out without replacing the crankshaft and according to an undifferentiated scheme, we introduce AMOIL additive into the engine oil M-10 G2 in a concentration determined by the nomogram (Fig. 3).

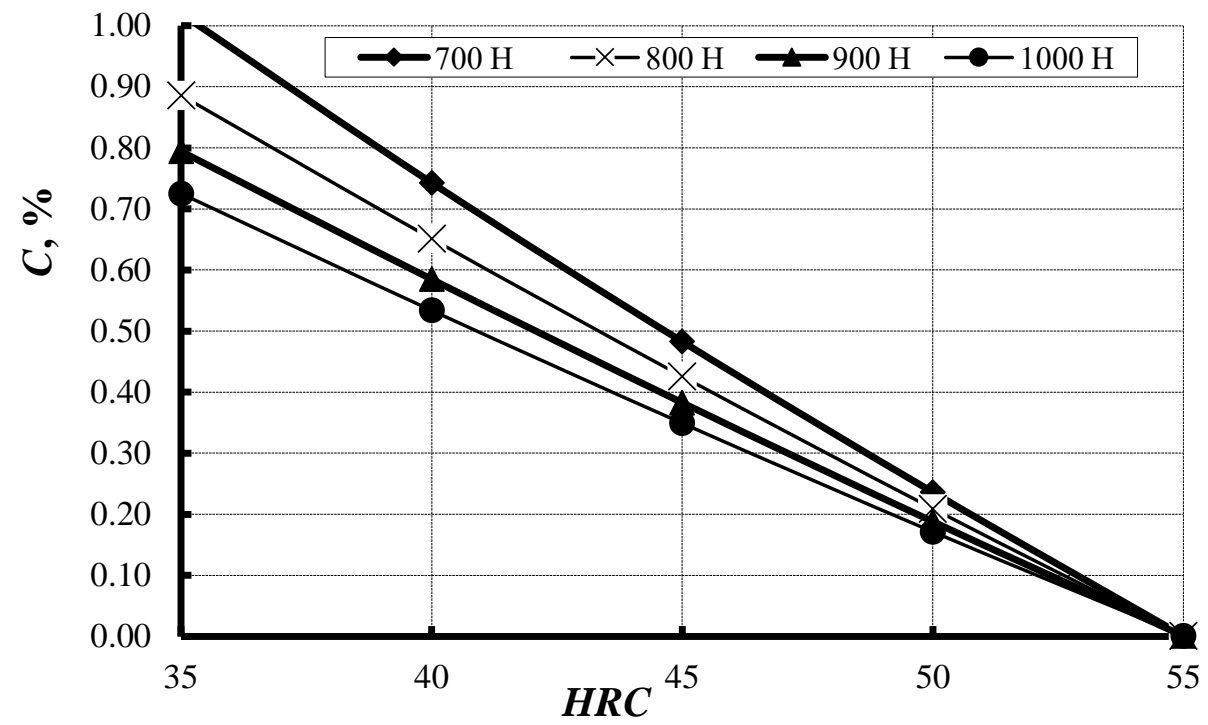

Fig. 3. Nomogram for selection of the minimum required concentration of the AMOIL additive to ensure the wear resistance of a crankshaft with a reduced hardness at the level of a new one with a hardness of $55 \mathrm{HRC}$ 
If after welding deposition the crankpin surface and restoring it to its nominal size the hardness of the surface layer does not reach the required values, the required durability can be ensured by introducing an additive of the required concentration into the engine crankcase oil.

\section{Conclusions}

Thus, there is a need to increase the engine life after repair. One of the rational ways to solve this problem is tribological compensation for the loss of the attached properties of parts during the operation of machines by applying additional anti-wear additives to oils. Determination of the anti-wear additive concentration in the engine oil, which provides the necessary increase in the wear resistance of parts that limit the engine life, should be carried out in relation to the friction surfaces of the crankshaft, as the weakest link after repair. The use of anti-wear additives to increase the engine life is justified when using relatively inexpensive additives that have a good anti-wear effect at low concentrations in the base engine oil.

To ensure the durability of the D-240 engine after major overhauls to the level of the new one it is recommended to use the AMOIL additive in the M-10 G2 engine oil in a concentration determined analytically from an equation or from a nomogram. In this case, the concentration is determined based on the hardness of the crankpins obtained after grinding or restoration in the load range of 800-1000 N.

The increase in wear of steel 45, caused by a decrease in hardness from 55 to $35 \mathrm{HRC}$, in the load range corresponding to the operating mode of the crankshaft, is tribologically compensated by the introduction of the anti-wear additive AMOIL in the engine oil in an amount not exceeding $1 \%$ by weight. This confirms the validity of theoretical calculations based on the results of laboratory tests.

\section{References}

[1] Strebkov S., Bondarev A., Slobodyuk A. Economic assessment of the recovery of aluminum radiator by gas-dynamic spraying //18th International Scientific Conference "Engineering For Rural Development" Proceedings, May 22-24 2019. Volume 18, pp. 1772-1779.

[2] Nekrasov S.S. Ways to improve the quality of engine repairs. // Technology and means of technical service of machines in the agro-industrial complex: Coll. of scientific papers. - M: MSAU named after V.P. Goryachkin, 2000, pp. 28-34.

[3] Strebkov S.V., Reliability of internal combustion engines and chemmotology of automobile gasoline: monograph/S.V. Strebkov, E.A. Morozov. - Belgorod: Publ BelSAA, 2011, 156 p.

[4] Sejkorova M., Hurtova I. Engine oil analysis - effective instrument to evaluate reliability of tractor engines //18th International Scientific Conference E"Engineering For Rural Development" Proceedings, May 22-24 2019. Volume 18, pp. 171-176.

[5] Bouden F.P., Tejbor D. Trenie i smazka tverdyh tel [Friction and lubrication of solids]. Perevod s anglijskogo. Pod redakciej doktora tekhnicheskih nauk I.V. Kragel'skogo. M., "Mashinostroenie", $1968,543 \mathrm{p}$.

[6] Wong V. W., Tung S. C. Overview of automotive engine friction and reduction trends-Effects of surface, material, and lubricant-additive technologies. Friction, 4(1), 2016. DOI: 10.1007/s40544016-0107-9.

[7] Il'in R. A., Chanchikov V. A., Guzhvenko I. N., Svekolnikov, S. A. Development and use of antiwear additions to lubricating oil in order to increase wear resistance of internal combustion engine moving contacts. Chemical and Petroleum Engineering, 53(7-8), 2017, pp. 464-468. DOI: $10.1007 / \mathrm{s} 10556-017-0364-0$.

[8] Putintsev S. V., Chirsky S. P., Pilatskaya S. S. New method of tribological testing lubricants and antifrictional additives. - 2019, DOI: 10.1007/978-3-319-95630-5_113

[9] Schulz J., Meyer D., Zimmer S. Investigations on critical additive concentrations in the tribocontact - influence of the steric structure of additives. [Ermittlungen zu kritischen Additiv-Konzentrationen im Tribokontakt - Einfluss des sterischen Aufbaus der Additive] Tribologie Und Schmierungstechnik, 66(4-5), 2019, pp. 64-69.

[10] Kryazhkov V.M., Reliability and quality of agricultural machinery. - M.: Agropromizdat, 1989, $365 \mathrm{p}$.

[11] Vodolazskaya N., Sharaya O. Wear resistance of cast iron parts due to modification of surface layer. Journal of Advanced Research in Technical Science, Iss. 18, 2020, pp. 33-36. 
[12] Skovorodin V. Ya., Tishkin L.V. Reference book on the reliability of agricultural machinery. - L.: Lenizdat, 1985, $204 \mathrm{p}$.

[13] Safonov V. V. Application of nanoscale materials in the operation of internal combustion engines: monograph./V. V. Safonov, E. K. Dobrin, V. A. Alexandrov, S. V. Safonova, A. A. Koltsov; Federal State Educational Institution "VPO" Saratov State Agricultural University named after N. I. Vavilov. - Saratov, 2006, 100 p.

[14] Ostrikov V. V., Multifunctional additive to motor oils.,/ Ostrikov V. V., Zimin A. G., Popov S. Yu., Safonov V. V..// Dvigatelestroyeniye, № 2 (256), 2014, pp. 35-37

[15] Strebkov S.V., Vetrov V.P. Formation of durability of restored machine friction units. // Resourcesaving technologies in the storage and processing of agricultural products: materials of the IV International Scientific and Practical Conference. seminar (July 4-5, 2002). - Orel: OrelGAU Publishing House, 2002, pp. 72-76.

[16] Pat. 2109799 Russian Federation, IPC 6 C10M129/40. Additive to lubricants and the method of its preparation/Strebkov S. V., Savchenko S. Ya., Malyutin S. A., Strebkova I. V.; applicant and patent holder Belgorod State Agricultural Academy. - No. 96114418/04; application No. 15. 07. 96; Publ. 27.04.98, Byul. No. 12, 7 p.

[17] Strebkov S. V., Vetrov V. P. Introduction of Amoil additive into oil reduces wear of friction units // Machinery and equipment for village. - 2007. - No. 6 (120), pp. 20-21. 